\title{
GRADUATE STUDENT AWARD FINALISTS-1995 MRS FALL MEETING
}

Jamie J. Arnold, Penn State University, "Are Single Molecular Wires Conducting?" (Symposium J)

Hamid Assadi, University of Cambridge, "Competitive Phase

Selection in Fe-Ni Alloy Dioplets" and "Development of Microstructure in Rapidly Solidified Intermetallics," (Symposium C)

Greg Carlson, University of Connecticut, "Polymer Nanocomposites of Surface-Functionalized Gold," (Symposium W)

Yong Chen, University of California, "Artificially Ordered AlAs $_{0.16} \mathrm{Sb}_{0.84}$ and InAs $0.93 \mathrm{Sb}_{0.07}$ Alloys Grown by Modulated Molecular Beam Epitaxy," (Symposium EE)

Brian H. Cumpston, Massachusetts Institute of Technology, "Stability of PPV Derivatives: The Effect of Side Group Functionalities" and "Photo-0xidation of Polythiophenes on Metal Substrates," (Symposium W)

Partha Sarathi Dutta, Indian Institute of Science, "Cathodoluminescence Spectroscopy for Evaluation of Defect Passivation in GaSb," (Symposium L)

Nora V. Edwards, North Carolina State University,"Analysis of Strain in GaN on $\mathrm{Al}_{2} \mathrm{O}_{3}$ and $6 \mathrm{H}-\mathrm{SiC}$," (Symposium AAA) Michael V. Glazov, University of Pennsylvania, "Temporal Instabilities (Dissipative Structures) in Cyclically Deformed Metallic Alloys," (Symposium Q)

Cécile Gourgon, Université J. Fourier, "Strain Effects in $\mathrm{CdTe} / \mathrm{CdZnTe}$ Nanostructures Fabricated by Nanolithography and Cleaved-Edge Overgrowth," (Symposium K)

Kalpana S. Katti, University of Washington, "A Novel

Technique for Determining Local Dielectric Function During Ferroelectric to Paraelectric Phase Transformation in $\mathrm{BaTiO}_{3}$ with a Transmission EELS," (Symposium T)

Matthew R. Linford, Stanford University,"Light-induced Formation of Alkyl Monolayers on Silicon," (Symposium 0)
Thomas S. McCauley, University of Alabama, "HighTemperature Homoepitaxial Diamond Film Growth Defects and Doping," (Symposium DD)

Sridhar Narayanaswamy, University of Michigan,"Temporal Evolution of Particle Shape in a Stressed Solid," (Symposium C)

Ivan W. Ong. The Johns Hopkins University, "Surface Enhanced Raman Spectroscopy of AgTCNQ Formed from $\mathrm{Ag}$ Micellar and Inverse Micellar Colloidal Systems," (Symposium W)

Daniel W. Pack, California Institute of Technology, "LigandInduced Reorganization and Protein Assembly in Synthetic Metal-Chelating Lipid Membranes," (Symposium 0)

Jeff Parrell, University of Wisconsin, "Controlled Decomposition and Reformation of the 2223 Phase in $\mathrm{Ag}$-Clad $(\mathrm{Bi}, \mathrm{Pb})_{2} \mathrm{Sr}_{2} \mathrm{CA}_{2} \mathrm{Cu}_{3} \mathrm{O}_{x}$ Tapes and Its Influence on the Microstructure and Critical Current Density," (Symposium F)

Fan Qian, University of Florida, "Deposition of Diamond-Like Carbon Films with Femtosecond Laser Pulses," (Symposium B)

Sundar Ramamurthy, University of Minnesota, "Interaction of Silicate Liquid with Sapphire Surfaces," (Symposium G) Paul G. Sanders, Northwestern University,"Structural Study of Nanocrystalline $\mathrm{Cu}, \mathrm{Pd}$, and Ni Compacts with Different Processing Histories," (Symposium E)

Steven R. Soss, Rensselaer Polytechnic Institute, "Electron Transport in Highly Textured Metal Films Grown by Partially lonized Beam Deposition," (Symposium I)

Bradford G. Storey, Northwestern University, "Structural Features of Defect Cascades in $\mathrm{YBa}_{2} \mathrm{Cu}_{3} \mathrm{O}_{x}$ as a Function of Oxygen Stoichiometry" and "A TEM Study of the Modulated Phase in $\mathrm{Hg}_{1-x} \mathrm{Cr}_{x} \mathrm{Sr}_{2} \mathrm{CuO}_{4+y}$ Superconductors," (Symposium F)
Ellad B. Tadmor, Brown University, "Multiple-Scale QuasiContinuum Finite Element Analysis of Defects in Crystals," (Symposium P)

Hark Hoe Tan, Australian National University, "IrradiationInduced Damage and Intermixing of GaAs-AIGaAs Quantum Wells," (Symposium A)

Patrick Tepesch, Massachusetts Institute of Technology, "A General Model to Predict Defect Arrangements in Complex Oxides: Application to Defect Fluorites," (Symposium P)

Scott A. Walker, University of California, "Ion-Driven SelfAssembly of Surfactant Mixtures into Ordered Phases," (Symposium N)

Ping-Chuan Wang, Columbia University, "Grain Orientation Mapping for Polycrystalline Films with an X-Ray Microdiffraction System," (Symposium I)

K. Scott Weil, Carnegie-Mellon University, "A Complexed Precursor Approach to the Synthesis of Ternary Transition Metal Nitrides," (Symposium S)

Yongwu Yang, Massachusetts Institute of Technology "Slow Relaxation Dynamics from Impulsive Stimulated Light Scattering Experiments," (Symposium M)

Zheng Jun Zhang, Tsinghua University, "Role of Interface in Ion Mixing/Thermal Annealing Induced Amorphization in Multilayers in Some Immiscible Metal Systems" and "Study of Metastable Alloy Formation in an Immiscible Y-Zr System by Ion Mixing/Thermal Annealing," (Symposium A)

Qun Zhong, University of Houston, "Defects in HighTemperature Superconductors: Characterization and Relations to Processing and Properties," (Symposium F)

\section{STAIB INSTRUMENTS, INC. PRODUCTS for SURFACE ANALYSIS}

RHEED SYSTEMS I RHEED Data Acquisition I AUGER I PEEM

\section{Precision RHEED Systems}

- Energy from 1 to $50 \mathrm{keV}$

- High beam current and stability

- Lowest divergence

- Remote controls

- Beam Rocking and Beam Blanking

- Differential pumping

- Deflection easily adjusted

- Computer interface

- Diagnostic port logic for free customer support

\section{Photo Electron Emission Microscope-PEEM}

- Fast, direct imaging microscopy with photoelectrons

- Variable magnification up to x1000

- Spatial resolution down to 200nm

- Imaging of the local work function and chemical state

- Video rate acquisition for dynamic studies of photoelectron yields

- UHV compatible with differential pumping capability for investigation of gas-surface reactions

- Excitation by UV lamp or synchrotron radiation

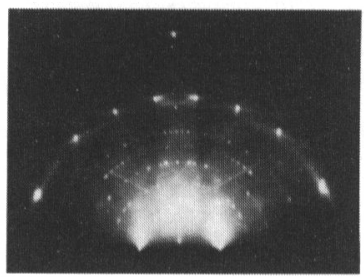

\section{RHEED Data Acquisition-RHEED Vision}

- RHEED oscillations on several spots simultaneously

- Dynamic multiple line scans

- Dynamic multiple spot profiling

- High speed CCD camera

- 8 and 16 bit image processing

- Data transfer and networking

- User friendly

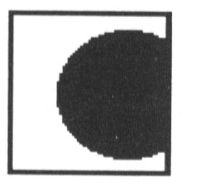

STAIB Instruments, Inc.

813 Diligence Drive, Suite 121E

Newport News, VA 23606

Phone: 804-873-0099 Fax: 804-873-0130

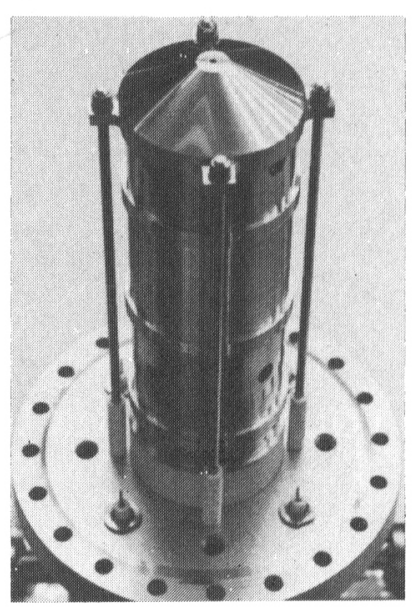




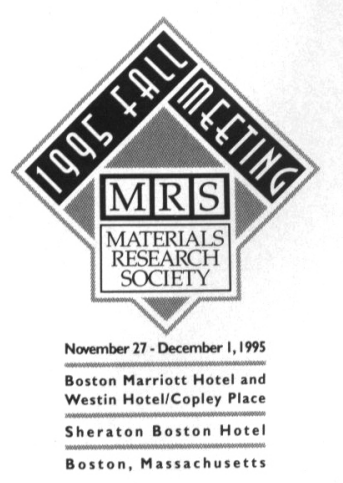

MRS Exhibit Boston Marriott Hotel and Westin Hotel/Copley Place • Sheraton Boston Hotel

As part of the 1995 MRS Fall Meeting, a major exhibit will be held to display analytical and processing equipment and publications closely paralleling the nature of the technical symposia. The technical program has been arranged to allow meeting participants ample opportunity to visit the exhibit.

Marriott Hotel, University Hall \& Atrium Lounge Tuesday, noon - 7:00 p.m.

Complimentary Reception 5:00 - 7:00 p.m.

Wednesday, 9:30 a.m. - 5:00 p.m.

Thursday, 9:30 a.m. - 2:00 p.m.

\section{Exhibit Hours:}

Westin Hotel, 3 \& 4 FI./Sheraton Hotel, Republic Foyer

Tuesday, 9:30 a.m. - 5:00 p.m.

Wednesday, 9:30 a.m. - 12:30 p.m. and 7:30 p.m. - 10:00 p.m.

Thursday, 9:30 a.m. - 12:30 p.m.

Partial List of 1995 Fall Exhibitors (as of October 2, 1995):

A\&N Corporation

\section{ABB Extrel}

Academic Press, Inc.

Advanced Control Systems

Corp.

Ahlburg Technical Equipment Corp./WELL

AIXTRON

AJA International

Akzo Nobel Chemicals, Inc.

Alcatel Vacuum Products, Inc.

Aldrich Chemical Company

Alfa Aesar

Allied High Tech Products, Inc.

American Chemical Society

American Institute of Physics (AIP)

APD Cryogenics, Inc.

Applied Engineering

Technologies, Ltd.

ASTeX/Applied Science and

Technology, Inc.

ATV Technology, Inc.

Balzers-Pfeiffer

Barnstead/Thermolyne

Bede Scientific/North Eastern Analytical

BIOSYM/Molecular Simulations

Blake Industries, Inc.

Buehler, Ltd.

Burleigh Instruments

Cambridge University Press

Cameca Instruments, Inc.

Ceramaseal

CHA Industries

Chapman \& Hall

Chemat Technology, Inc.

Commonwealth Scientific Corporation

The Cooke Corporation

Cornell Theory Center

Cree Research, Inc.

Cressington Scientific Instruments, Inc.

Cryomech, Inc.

CVD Products, Inc.

Cymer Laser Technologies

DCA Instruments
Denton Vacuum, Inc.

Digital Instruments

Duniway Stockroom Corp.

E S Microware

Edwards High Vacuum

International

\section{Elchema}

Elsevier Science

EMCORE Corporation

EPI MBE Products Group

Evans East

FEl Company

E.A. Fischione Instruments, Inc.

Fisons Instruments

Gatan, Inc.

Gelest, Inc.

Gordon \& Breach Publishers

Harris Diamond Corporation

Heraeus Amersil, Inc.

High Voltage Engineering

Europa B.V.

Hitachi Scientific Instruments

Huntington Mechanical

Laboratories

IBM Analytical Services

Implant Sciences Corporation

Inel, Inc.

Innovative Technology, Inc.

Inorgtech, Ltd.

Institute for Scientific

$$
\text { Information (ISI) }
$$

Institute of Physics Publishing (IOP)

Instron Corporation

Instruments SA, Inc./ Jobin-Yvon-Spex

Ion Tech, Inc.

Janis Research Company, Inc.

JCPDS-ICDD

JEOL USA, Inc.

Johnsen Ultravac

k-Space Associates, Inc.

Keithley Instruments

Kimball Physics, Inc.

Kluwer Academic Publishers

Kratos Analytical, Inc.

Lake Shore Cryotronics, Inc.
Lambda Physik, Inc.

Kurt J. Lesker Company

Leybold Inficon, Inc.

LUXTRON Corporation

M. Braun, Inc.

Magnet Sales \& Manufacturing

Maxtek, Inc.

McPherson, Inc.

MDC Vacuum Products

Corporation

Media Cybernetics

Melles Griot

Micro Instrument Company

Micro Photonics, Inc.

Microcal Software, Inc.

Mikron Instrument $\mathrm{C}_{0}$., Inc.

MKS Instruments, Inc.

MMR Technologies

MR Semicon, Inc.

n \& k Technology, Inc.

Nanophase Technologies Corp.

National Electrostatics Corp.

Neocera, Inc.

New Focus, Inc.

Nicolet Instrument Corporation

NORAN Instruments

Omicron Associates

Oxford Applied Research

Oxford Instruments, Inc.

Oxford University Press

Park Scientific Instruments

Phase Shift Technology

Philips Electronic Instruments Co.

Philips Semiconductors/ Materials Analysis Group

Physical Electronics

Plasma Sciences, Inc.

Plasmaterials, Inc.

Plenum Publishing Corporation

Princeton Gamma-Tech, Inc.

Princeton Instruments, Inc.

Princeton Research Instruments

Princeton Scientific Corp.

Pure Tech, Inc.

Quantum Design

Quesant Instrument

Corporation
Research \& PVD Materials

Corporation

RHK Technology

Rigaku/USA, Inc.

RJ Lee Instruments, Ltd.

Schumacher

Scientific Instruments, Inc.

Scintag, Inc.

SciVision

Semiconductor Processing Co.

Siemens Industrial

Automation, Inc.

SKION Corporation

Solartron Instruments, Inc.

SOPRA, Inc.

South Bay Technology

Springer-Verlag New York, Inc.

Staib Instruments, Inc.

Structure Probe, Inc./

SPI Supplies

Superconductive Components/

Target Materials, Inc.

Surface/Interface, Inc.

SVT Associates

Sycon Instruments, Inc.

Taylor \& Francis

TEC

Technotrade International, Inc.

Telemark

Tencor Instruments

TexSEM Laboratories, Inc.

Textron Defense Systems

Thermionics Laboratory, Inc.

TopoMetrix

Union Carbide Crystal

Products

Varian Vacuum Products

VAT, Inc.

VCH Publishers, Inc.

Virginia Semiconductor, Inc.

Voltaix, Inc.

Wavemat, Inc.

John Wiley \& Sons, Inc.

World Scientific Publishing

Co., Inc.

X-Ray Optical Systems, Inc.

Zygo Corporation 


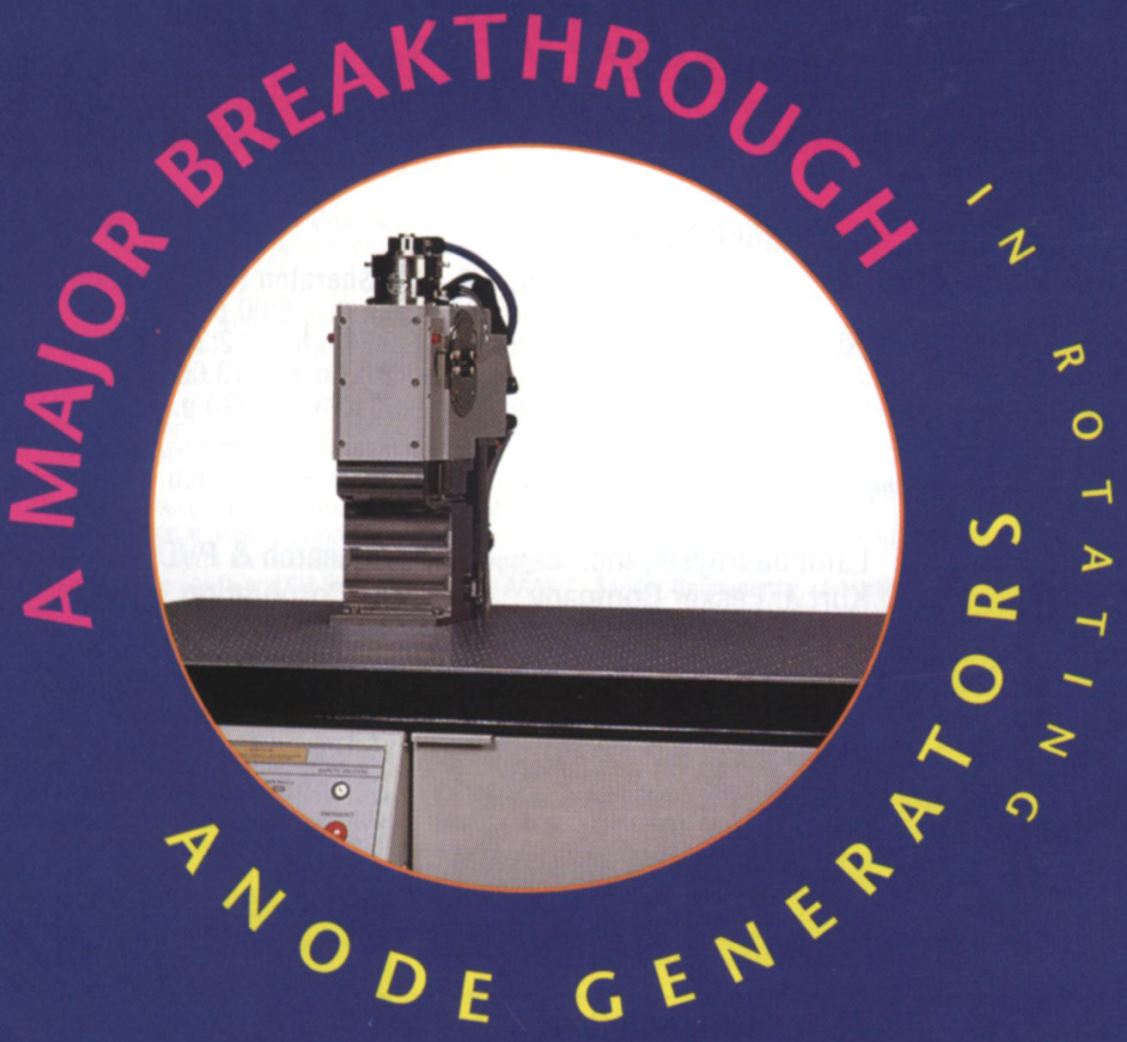

(1)

$\$$

D

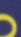

$-$

3

(1)

อ

?

요

(D)

๑

כ

$\sigma$

๑

Visit MRS Exhibit

Booth No. U901
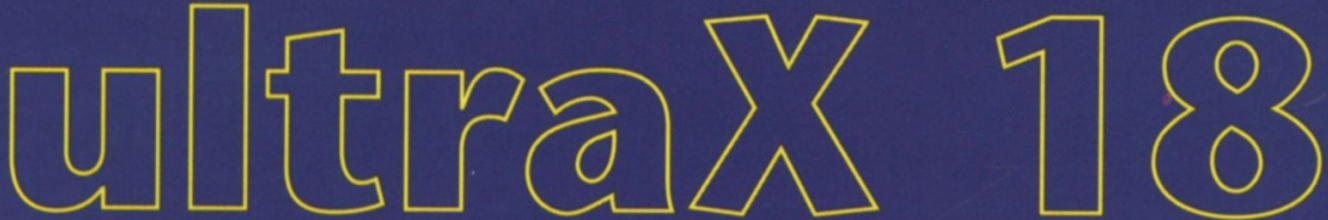

ค

(1)

(1)

(D)

Rigaku continues as the clear leader in analytical $\mathrm{x}$-ray rotating anode generators with the introduction of the "ultraX 18". A major breakthrough in design has resulted in a compact, light-weight, table-top anode assembly which can be mounted on a breadboard. This means the assembly can be readily moved and its orientation adjusted so that it can be combined with a wide range of instrumentation for a variety of applications. The total system design also provides higher stability and lower maintenance.

The ultraX is a high-frequency $18 \mathrm{~kW}$ rotating anode generator operating at $60 \mathrm{kV} / 300 \mathrm{~mA}$ or $40 \mathrm{kV} / 450 \mathrm{~mA}$; several different anode materials are available. Other options include choice of horizontal or vertical configuration, point and or line focus and focal spot size. 


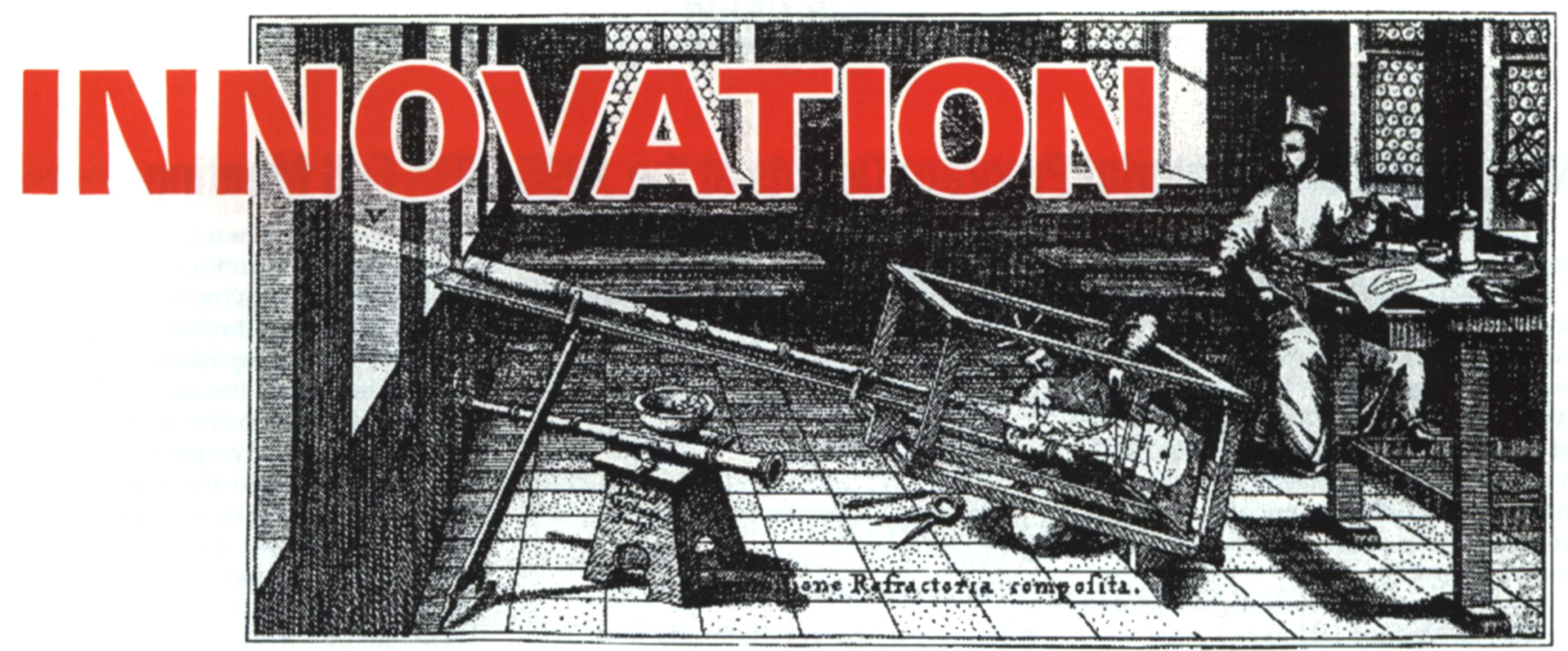

Quesant Instrument Corporation has improved the scanning probe microscope through innovation. Our QScopes ${ }^{\mathrm{TM}}$ were designed with new features and reduced costs.

New features include Windows ${ }^{\mathrm{TM}}$ based software, built-in upgradability, rastering the probe not the sample, top down view of the probe and the sample, solid granite stages, interchangeable scan heads and tracking the probe with the laser beam.

But benefits sell our products. These include: scanning three minutes after you turn the power on, little or no sample preparation, interchangeable scan heads, probe changes in one minute and the ability to accurately place the probe where you want it, whether it be the end of a pin, a neuron or an 8 " semiconductor wafer.

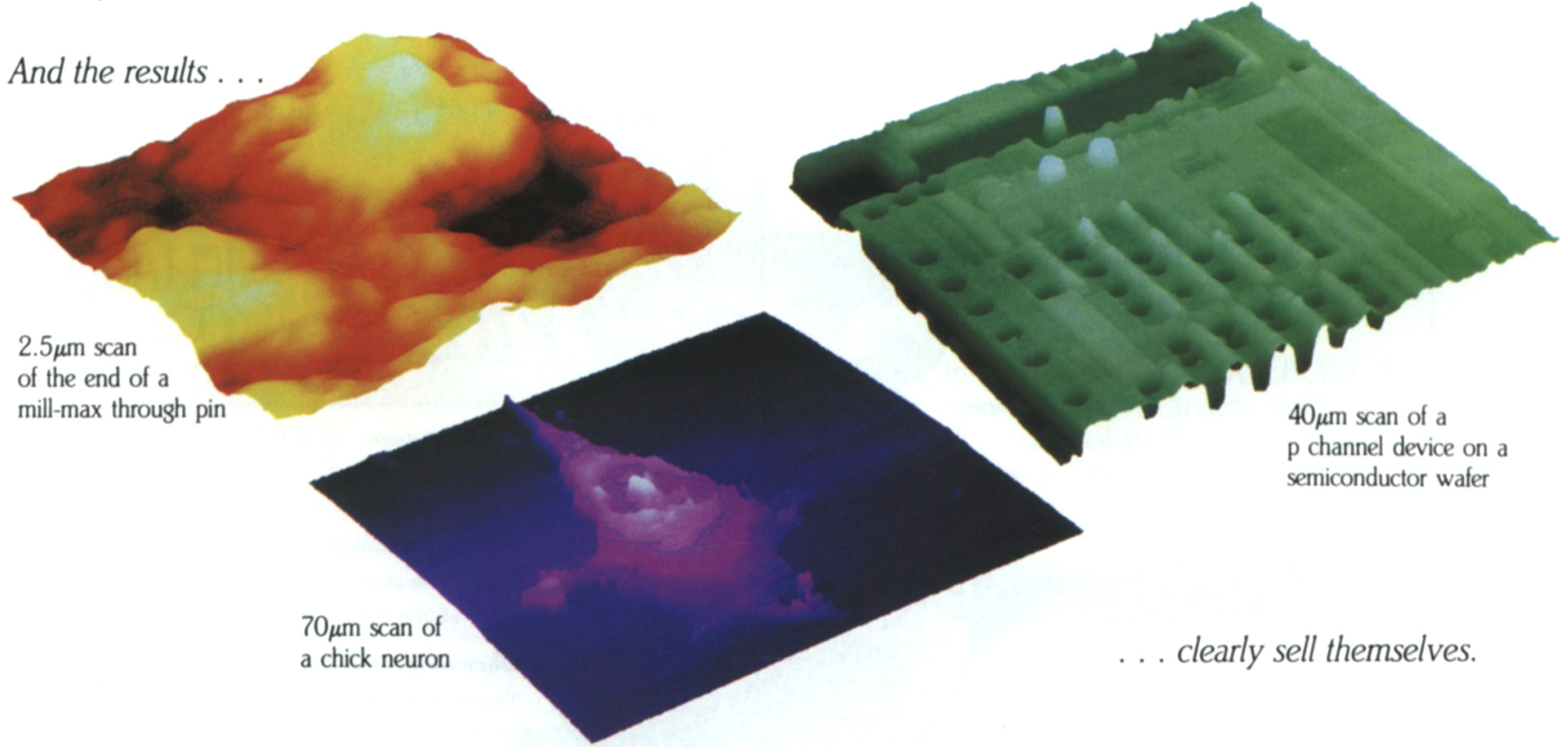

Our team of scientists and engineers will continue to bring you the latest in technology.

Quesant products come with a money back guarantee - if we don't perform, you don't pay.

Give us a call. Find out what the latest innovations are.

By the way. About the cost; our complete SPM systems start at under $\$ 30,000$.

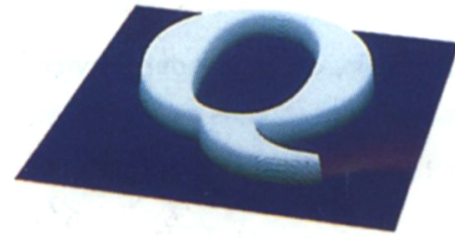

Quesant Instrument Corporation

28038 Dorothy Drive Agoura Hills, CA 91301

Phone: 818-597-0311 Fax: 818-991-5490

Circle No. 44 on Reader Service Card. 